\title{
Association of Hypertension and its risk factor in Type II diabetes mellitus patients
}

\author{
Seema Singh ${ }^{1}$, Nitin Ranjan Gupta ${ }^{2}$, Syed Tahseen Raza ${ }^{3}$, Avadh Kapoor ${ }^{4}$, Pooja Singh \\ ${ }^{1}$ Professor and Head, ${ }^{3}$ Tutor, ${ }^{4}$ Assistant Professor, Department of Physiology, Era's Lucknow Medical College \& \\ Hospital, Lucknow, Uttar Pradesh, India, ${ }^{2}$ Associate Professor, Department of Internal Medicine, Hind Institute of \\ Medical Sciences and Research, Sitapur, India, ${ }^{5}$ Assistant Professor, Department of Biotechnology, Uttaranchal \\ College of Science and Technology, Uttarakhand, India
}

\section{A B S T R A C T}

Background: There are few reports in India about the correlation of hypertension, its risk factors and its relationship with type II diabetes. Several studies have shown that Type II diabetes in India is increasingly widespread. Aims and Objective: The main purpose of this research is to determine the association between hypertension and type II mellitus diabetes. Materials and Methods: The Department of Physiology, Era Medical College \& Hospital, Lucknow and the Department of Internal Medicine, Hind Institute of Medical Sciences and Research, Sitapur, performed a cross-sectional study on 520 patients with type II diabetes. The structured questionnaire was prepared to collect history of hypertension, social and demographical parameters and diabetes duration. A trained staff has measured anthropometric data like height, weight and also took blood pressure by digital blood pressure monitor (CITIZEN-CH-432). Results: This study indicated a significant $(p<0.001)$ relationship between $\mathrm{BMI}$ and hypertension in diabetes mellitus II patients. This study has also shown significant relationship between physical activity and hypertension in diabetes mellitus patients. The logistic regression study demonstrated that hypertension in diabetes mellitus patients has been positively associated with age $(p<10-4)$ sensitivity level $(p<10$ 3 ) and period of diabetes $(p<10-2)$. Conclusion: Hypertension is a common issue among diabetic Indians. This research focused primarily on the association of hypertension and its related risk factors in patients with diabetes. The study showed that hypertension in diabetic patients is associated with age, physical activity, awareness level and BMI. More studies

Access this article online

Website:

http://nepjol.info/index.php/AJMS DOI: 10.3126/ajms.v12i1.30508

E-ISSN: 2091-0576

P-ISSN: $2467-9100$

Copyright (c) 2021 Asian Journal of Medical Sciences

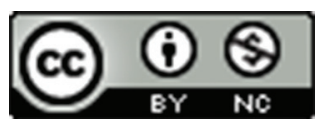

This work is licensed under a Creative Commons Attribution-NonCommercial 4.0 International License. on larger sample sizes are needed to validate the current findings.

Key words: Hypertension; Type II diabetes; BMI

\section{INTRODUCTION}

Type II Diabetes is estimated to affect 150 million people worldwide. The prevalence is increasingly growing due to improvements in the diagnosis criteria. ${ }^{1}$ Type II diabetic patients have a high risk of premature death from kidney failure, stroke and cardiovascular disease. ${ }^{2}$ Hypertension is a well-recognized risk factor for cardiovascular disease in adults along with diabetes. ${ }^{1}$ stroke and ischemic heart disease. Diabetes and hypertension develops together and hence hypertension is the key source of premature mortality in both developing and developed countries. ${ }^{3}$ In the diabetic population the incidence of hypertension is greater than in the non-diabetic population $^{4,5}$ (Figure. 1).

\section{MATERIALS AND METHODS}

\section{Subjects and collection of samples}

The present research was performed in the Department of Physiology at Era Medical College \& Hospital, Lucknow and Department of Internal Medicine, Sitapur, Hind Institute of Medical Sciences and Study. In this study, patient of fasting blood glucose $\geq 126 \mathrm{gm} / \mathrm{dl}$ have been included in this study. Total 520 Type II diabetic patients with hypertensive symptoms have been enrolled in this study 


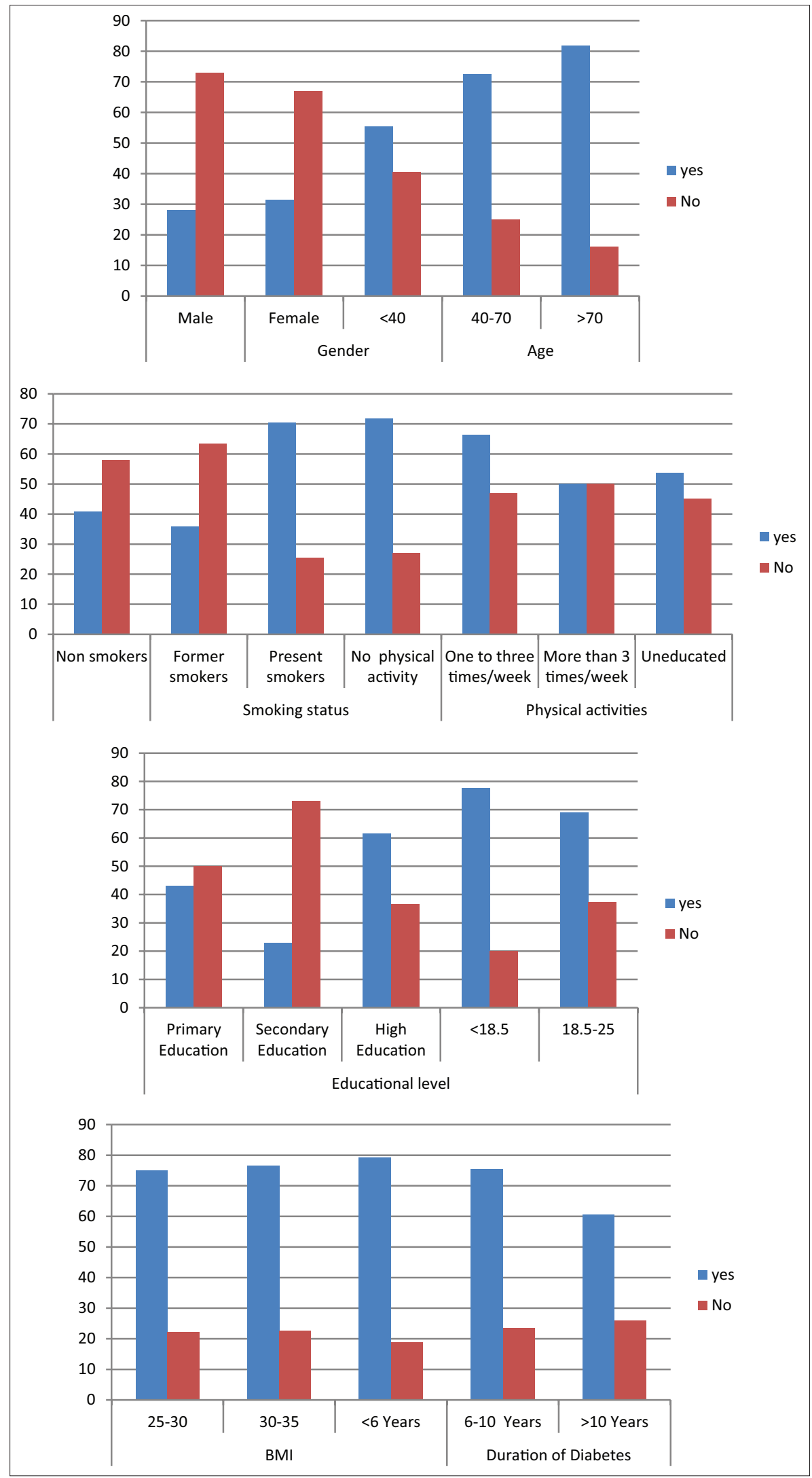

Figure 1: Graphical representation of Sociodemographical parameters and Hypertension in Diabetes mellitus II patients

and have given their written consent in writing. The research was accepted by ELMC\&H Ethical Committee, Lucknow.
For this analysis the patients were chosen according to the parameters of inclusion and exclusion as seen below. 


\section{Inclusion criteria}

Within this study were included all type II Diabetic patients displaying signs of hypertension, able to participate in this study.

\section{Exclusion criteria}

Major/chronic disorder (Asthma, Tuberculosis, seizure and renal disorders) and patients who have any immunodeficiency disorder.

For this study, a professional staff conducted the tests and took two blood pressure readings from each patient, and then the average reading of all readings was taken. Hypertension is classified as $\geq 140 \mathrm{mmHg}$ systolic BP and / or level of diastolic BP $\geq 90 \mathrm{mmHg}$. The grey area which falls between 120-139 mmHg systolic BP and 80-89 $\mathrm{mmHg}$ diastolic BP, is known as "prehypertension" ., Even Prehypertension is not in itself a pathological disorder, prehypertensive subjects are more at risk of developing HTN. ${ }^{8}$ These results have been analyzed by version 16 of SPSS. The chi square method was used to evaluate the relation between different variables and obtained a $\mathrm{p}$ value of 0.05 or less.

\section{RESULTS}

\section{Questionnaire}

This study included 520 diabetic participants as described in Table 1.A proposed questionnaire was designed to collect information on social and demographic criteria such as (gender, age and educational level), diabetic period, smoking habit, and history of hypertensions. A specialized worker measured measurements of anthropometry such as weight and height etc. BMI was also measured by the professional workers by dividing weight (kilograms) by height in square meters. Standardized digital blood pressure monitor (CITIZEN-CH-432) have been used to measure the blood pressure.

This study recruited 520 hypertensive diabetic participants. 30.1 percent were females in this sample, and 69.0 percent were males (Figure.1).

Half the population (50.0 per cent) had experienced overt diabetes for less than 10 years. Unaware individuals were placed at the greater risk of hypertension in contrast to conscious people $(\mathrm{P}<10-3)$. Smoking status is greater in

\begin{tabular}{|c|c|c|c|c|}
\hline \multirow{3}{*}{$\begin{array}{l}\text { Socio-demographical } \\
\text { parameters }\end{array}$} & \multirow{3}{*}{$\begin{array}{c}\text { Total } \\
\mathbf{N} \%\end{array}$} & \multicolumn{2}{|c|}{ Hypertension } & \multirow[t]{3}{*}{$p$-value } \\
\hline & & Yes & No & \\
\hline & & $\mathrm{N} \%$ & $\mathrm{~N} \%$ & \\
\hline \multicolumn{5}{|l|}{ Gender } \\
\hline Male & $360(69.0 \%)$ & $100(28 \%)$ & $260(73.0 \%)$ & \\
\hline Female & $160(30.1 \%)$ & $50(31.3 \%)$ & $110(67.0 \%)$ & 0.30 \\
\hline \multicolumn{5}{|l|}{ Age } \\
\hline$<40$ & $130(24.2 \%)$ & $74(55.5 \%)$ & $56(40.5 \%)$ & \\
\hline $40-70$ & $150(28.8 \%)$ & $110(72.6 \%)$ & $40(25.1 \%)$ & $<10^{-3}$ \\
\hline$>70$ & $240(47.1)$ & $200(81.8 \%)$ & $40(16.1 \%)$ & \\
\hline \multicolumn{5}{|l|}{ Smoking status } \\
\hline Non smokers & $30(18.5 \%)$ & $12(40.9)$ & $18(58.0 \%)$ & \\
\hline Former smokers & $10(7.5 \%)$ & $4(35.7 \%)$ & $6(63.3 \%)$ & $<10^{-2}$ \\
\hline Present smokers & $480(70.6 \%)$ & $340(70.5 \%)$ & $140(25.5 \%)$ & \\
\hline \multicolumn{5}{|l|}{ Physical activities } \\
\hline No physical activity & $434(80.7 \%)$ & $316(71.8 \%)$ & $118(27.0 \%)$ & \\
\hline One to three times/week & $50(10.4)$ & $37(66.3 \%)$ & $13(47.0 \%)$ & $<0.01$ \\
\hline More than 3 times/week & $36(5.7 \%)$ & $18(50.1 \%)$ & $18(50.0 \%)$ & \\
\hline \multicolumn{5}{|l|}{ Educational level } \\
\hline Uneducated & $12(2.3 \%)$ & $7(53.8 \%)$ & $5(45.2 \%)$ & \\
\hline Primary education & $62(11.6 \%)$ & $31(43.0 \%)$ & $31(50.0 \%)$ & $<10^{-3}$ \\
\hline Secondary education & $406(76.1 \%)$ & $101(23.0 \%)$ & $305(73.0 \%)$ & \\
\hline High education & $40(7.5 \%)$ & $15(61.5 \%)$ & $25(36.5 \%)$ & \\
\hline \multicolumn{5}{|l|}{ BMI } \\
\hline$<18.5$ & $9(1.8 \%)$ & $7(77.8 \%)$ & $2(20 \%)$ & \\
\hline $18.5-25$ & $125(24.2 \%)$ & $80(69.1 \%)$ & $45(37.3 \%)$ & 0.01 \\
\hline $25-30$ & $223(42.7 \%)$ & $159(74.9 \%)$ & $64(22.1 \%)$ & \\
\hline $30-35$ & $163(31.2 \%)$ & $127(76.4 \%)$ & $36(22.5)$ & \\
\hline \multicolumn{5}{|l|}{ Duration of diabetes } \\
\hline$<6$ Years & $123(23.5)$ & $102(79.3)$ & $21(18.7)$ & $<10^{-2}$ \\
\hline 6-10 Years & $133(24.2)$ & $100(75.3)$ & $33(23.5)$ & \\
\hline$>10$ Years & $264(50.0)$ & $168(60.5)$ & $96(25.9)$ & \\
\hline
\end{tabular}


hypertensive patients in comparison to non-hypertensive patients. Hypertension get increased according to age as shown in Table I and Figure.1. A significant correlation $(\mathrm{p}<0.01)$ have been observed for physical activities among hypertensive and non-hypertensive patients. The other factor BMI has also shown significant correlation between hypertensive and non-hypertensive participants with diabetes. Diabetic patients participated in this study has represented that 10 years diabetic patients are more hypertensive in comparison to 6 years diabetic patients; hence this study have shown the positive correlation between Hypertension and Diabetes.

\section{DISCUSSION}

Stress activates sympathetic system, which contributes to elevated blood pressure, the blood pressure returns to normal (or near normal) level after the stress is removed. ${ }^{9}$

Usually, Hypertension occurs simultaneously with diabetes in population. ${ }^{10}$ The present research reflects that hypertension in Indian patients with type 2 diabetes is a general issue. Hence, we reported a positive association between hypertension and BMI, diabetes age and length. This study found high rate of hypertension in 60 years old diabetic patients. This may be different for each country, because of different types of methods, surveillance, characteristics of population and ethnic varieties. ${ }^{11}$ Hypertension was also associated with age amongst type II diabetic patients, this association were validated by different literatures of research and different findings of other studies. ${ }^{12,13}$ In fact, hypertension and obese diabetes have raises the risk of coronary disorders and a few other morbidities. ${ }^{14,15}$ In diabetic persons, hypertension has features reminiscent of hypertension in the elderly. In all cases, hypertension is distinguished by improved vascular resistance. ${ }^{16-18}$ and acute systolic hypertension is found in young diabetic patients, as well as in the elderly. Early atherosclerosis is likely to lead to early vascular ageing improvements in diabetic people with hypertension. ${ }^{19}$ This premature ageing of diabetics is likely to play a key role in the comparatively high incidence of elevated systolic hypertension and diminished baroreceptor sensitivity in young people with diabetes. The latter arises before clinical neurological dysfunction progresses in young diabetics. Reduced baroreceptor reflex sensitivity and impaired cardiac innervation can partially explain the significant instability in blood pressure and the susceptibility to orthostatic hypotension found in diabetics with hypertension. ${ }^{20,21}$ These latter traits, also found in elderly patients with hypertension, signify premature cardiovascular system ageing in diabetic patients with co-existing hypertension. Other variables contribute to the pathophysiology of hypertension in diabetes, total exchangeable sodium, plasma renin activity, plasma norepinephrine, plasma aldosterone, susceptibility to baroreceptors, vascular compliance, peripheral vascular resistance, vascular pressure response, insulin resistance, irregular ca resistance, in addition to premature vascular ageing and its effect on vascular rigidity and resistance.

Our results showed that, hypertension is higher in unaware people in compare of aware people towards health. Smokers in this study have shown a positive correlation with hypertension in comparison to nonhypertensive patients with diabetes. Our study showed hypertension is linked with diabetes duration. This research draws attention to the value of blood pressure assessment and also the understanding of diabetic patient care. Hypertension occurs in the U.S. population in about 30 percent of patients with type 1 diabetes, and in 50 percent to 80 percent of patients with type 2 diabetes. ${ }^{22}$ A prospective U.S. observational study found that type 2 diabetes mellitus was almost 2.5 times more likely to occur in hypertensive subjects than in subjects with average blood pressure. ${ }^{23}$ In fact, diabetes and hypertension are seen more often in the same person than happens by chance, while the overlap between dysglycemia and high blood pressure is far more significant than between diabetes and hypertension. ${ }^{24}$

In our study, most of the patients are still under uncontrolled hypertension with formerly diagnosed hypertension. This finding is same as findings of other studies. ${ }^{25-27}$ Our study indicated that physical activities decrease the chances of hypertension. The study also indicated a significant correlation $(\mathrm{p}<0.01)$ between hypertension and physical activities. The results also show that BMI in type II Diabetic patients were substantially $(\mathrm{p}<0.01)$ associated with hypertension, so a large number of trials on large numbers of patients with hypertensive diabetic mellitus are required to determine the causal association between the patients with hypertension, blood pressure, BMI and diabetes mellitus.

\section{CONCLUSION}

The frequency and prevalence of undiagnosed hypertension is very high among Indian population with type II diabetes mellitus. This study indicated that hypertension is positively correlated with physical activity and BMI in diabetes mellitus patients. This study also proved that hypertension increases with age. Therefore, it has been concluded that hypertension is frequent in diabetes mellitus patients. And 
more studies are required on larger sample size to validate these results.

\section{ACKNOWLEDGEMENT}

The authors take this opportunity to thank Department of Physiology, Era Medical College \& Hospital, Lucknow and the Department of Internal Medicine, Hind Institute of Medical Sciences and Research, Sitapur, to carry out the present study.

\section{REFERENCES}

1. King H, Aubert RE and Herman WH. Global burden of diabetes, 1995-2025: prevalence, numerical estimates, and projections. Diabetes Care. 1998 ;21(9):1414

https://doi.org/10.2337/diacare.21.9.1414

2. Genuth S. A case for blood glucose control. Advances in internal medicine. 1995; 40:573-623.

3. Libby P, Nathan DM, Abraham K and Brunzell JD. Report of the National Heart, Lung and Blood Institute: National Institute of Diabetes and Digestive and Kidney Diseases Working Group on Cardiovascular Complications of DM. Circulation. 2005; 111:3489-3493.

https://doi.org/10.1161/CIRCULATIONAHA.104.529651

4. Paul B, Sapra B, Maheswari S and Goyal RK. Role of Losartan therapy in the management of diabetic hypertension. The Journal of the Association of Physicians of India. 2000; 48: 514-517.

5. Pickering TG, Eguchi K and Kario K. Masked hypertension: a review. Hypertens Res. 2007; 30:479-488.

https://doi.org/10.1291/hypres.30.479

6. Kumar MR, Shankar R and Singh S. Hypertension among the adults in rural Varanasi: a cross-sectional study on prevalence and health seeking behavior. Indian Journal of Preventive and Social Medicine. 2016; 47(1-2): 78-83.

7. Chobanian AV, Bakris GL, Black HR, Cushman WC, Green LA, Izzo Jr JL, et al. Seventh report of the Joint National Committee on prevention, detection, evaluation, and treatment of high blood pressure. Hypertension. 2003; 42(6): 1206-1252.

https://doi.org/10.1161/01.HYP.0000107251.49515.c2

8. Erem C, Hacihasanoglu A, Kocak M, Deger O and Topbas M. Prevalence of prehypertension and hypertension and associated risk factors among Turkish adults: Trabzon hypertension study. Journal of Public Health. 2009; 31(1): 47-58.

https://doi.org/10.1093/pubmed/fdn078

9. Kapoor A and Singh S. To study autonomic variability in offsprings of hypertensive parents in Lucknow using cold pressor test. Indian Journal of Clinical Anatomy and Physiology. 2019; 6(2):139-143.

https://doi.org/10.18231/j.ijcap.2019.032

10. Mubarak FM, Froelicher ES, Jaddou HY and Ajlouni KM. Hypertension among 1000 patients with type 2 diabetes attending a national diabetes center in Jordan. Annals of Saudi medicine. 2008;28(5):346-351.

https://doi.org/10.5144/0256-4947.2008.346

11. V, Kamalakannan D, Holland MR and Singh BM. Does ethnic origin have an independent impact on hypertension and diabetic complications? Diabetes Obes Metab. 2006; 8(2):214-219. https://doi.org/10.1111/j.1463-1326.2005.00485.x

12. Davis TM, Stratton IM, Fox CJ, Holman RR and Turner RC. U.K. Prospective Diabetes Study 22: Effect of age at diagnosis on diabetic tissue damage during the first 6 years of NIDDM. Diabetes Care.1997;20(9):1435-1441. https://doi.org/10.2337/diacare.20.9.1435

13. Hillier TA and Pedula KL. Characteristics of an adult population with newly diagnosed type $2 \mathrm{DM}$ : the relation of obesity and age of onset. Diabetes Care. 2001; 24(9):1522-1527. https://doi.org/10.2337/diacare.24.9.1522

14. Brown CD, Higgins M, Donato KA, Rohde FC, Garrison R, Obarzanek $\mathrm{E}$, et al. Body mass index and the prevalence of hypertension and dyslipidemia. Obesity Research. 2000;8(9):605-619.

https://doi.org/10.1038/oby.2000.79

15. Must A, Spadano J, Coakley EH, Field AE, Colditz G and Dietz WH. The disease burden associated with overweight and obesity. JAMA. 1999;282(16):1523-1529. https://doi.org/10.1001/jama.282.16.1523

16. Sowers JR, Levy J and Zemel MB. Hypertension and diabetes. Med Clin N Am. 1988; 72:1399-1414. https://doi.org/10.1016/S0025-7125(16)30714-3

17. Sowers JR. Hypertension in the elderly. Am J Med. 1987; 82(supp II B): I-8. https://doi.org/10.1016/0002-9343(87)90265-8

18. Weidman P, Beretta-Piccoli $C$ and Trost BN. Pressor factors and responsiveness in hypertension accompanying diabetes mellitus. Hypertension. 1985;79(suppl II):II-33-II-42. https://doi.org/10.1161/01.HYP.7.6_Pt_2.II33

19. Schonfeld G. Diabetes, lipoproteins, and atherosclerosis. Metabolism. 1985; 34:45-50. https://doi.org/10.1016/S0026-0495(85)80009-3

20. Eckberg DL, Harkins SW, Fritsch JM, Musgrave GE and Gardner DF. Baroreflex control of plasma norepinephrine and heartperiod in healthy subjects and diabetic patients. J Clin Invest. 1986; 78:366-374. https://doi.org/10.1172/JCl112586

21. Wiegmann TB, Herron KG, Chonko AM, MacDougall ML and Moore WV. Recognition of hypertension and abnormal bloodpressure burdened with ambulatory blood pressure recordings in type I diabetes mellitus. Diabetes. 1990; 39:1556-1560.

https://doi.org/10.2337/diab.39.12.1556

22. Landsberg $L$ and Molitch $M$. Diabetes and hypertension: pathogenesis, prevention and treatment. Clin Exp Hypertens. 2004;26:621-628. https://doi.org/10.1081/CEH-200031945

23. Gress TW, Nieto FJ, Shahar E, Wofford MR and Brancati FI. Hypertension and antihypertensive therapy as risk factors for type 2 diabetes mellitus. Atherosclerosis Risk in Communities Study. N Engl J Med. 2000; 342:905-912. https://doi.org/10.1056/NEJM200003303421301

24. Cheung BMY, Wat NMS, Tso AWK, Tam S, Thomas GN, Leung GM, et al. Association between raised blood pressure and dysglycemia in Hong Kong Chinese. Diabetes Care. 2008; 31:1889-1891. https://doi.org/10.2337/dc08-0405

25. Cowie CC and Harris MI. Physical and metabolic characteristics of persons with diabetes. In: Harris MI, ed. Diabetes in America. 2nd ed. Bethesda, Md: National Institutes of Health, National 
Institutes of Diabetes and Digestive and Kidney Disease; 1995:117-164. NIH publication 95-1468 Page number not for citation purposes 6

26. Sprafka JM, Bender AP and Jagger HG. Prevalence of hypertension and associated risk factors among diabetic individuals. The Three-City Study. Diabetes Care. 1988;11(1): 17-22. https://doi.org/10.2337/diacare.11.1.17

27. Hypertension in Diabetes Study (HDS): I. Prevalence of hypertension in newly presenting type 2 diabetic patients and the association with risk factors for cardiovascular and diabetic complications. J Hypertens. 1993;11(3):309-317. https://doi.org/10.1097/00004872-199303000-00012

\section{Author's Contribution:}

SS - Concept and design of the study; interpreted the results, prepared first draft of manuscript and critical revision of the manuscript; NRG - Statistically

analyzed and interpreted; reviewed the literature and manuscript preparation; STR, AK - Design of the study, statistically analyzed and interpreted, preparation of manuscript and revision of the manuscript; PS - Concept and coordination of the overall study.

\section{Work attributed to:}

Department of Physiology, Era Medical College \& Hospital, Lucknow and the Department of Internal Medicine, Hind Institute of Medical Sciences and Research, Sitapur.

\section{Orcid ID:}

Prof. Seema Singh - (1) https://orcid.org/0000-0003-0541-6331

Dr. Pooja Singh - (1) https://orcid.org/0000-0003-4394-8961

Source of funding: Era Medical College \& Hospital, Lucknow, Conflict of Interest: None. 